\title{
Crystallographic, thermal and spectroscopic characterization of the anhydrous thiourea-barbituric acid and thiourea-2-thiobarbituric acid co-crystals
}

\author{
Nicolay N. Golovnev ${ }^{a}$, Maxim S. Molokeev ${ }^{b, a, c^{*}}$, Irina V. Sterkhova ${ }^{d}$, Maxim K. Lesnikov ${ }^{a}$ \\ ${ }^{a}$ Siberian Federal University, 79 Svobodny Ave., Krasnoyarsk 660041, Russia \\ ${ }^{b}$ Laboratory of Crystal Physics, Kirensky Institute of Physics, Federal Research Center KSC SB \\ RAS, bld. 38 Akademgorodok 50, Krasnoyarsk 660036, Russia \\ ${ }^{c}$ Department of Physics, Far Eastern State Transport University, 47 Seryshev Str., Khabarovsk \\ 680021, Russia \\ ${ }^{d}$ Favorsky Institute of Chemistry, Siberian Branch, Russian Academy of Sciences, 1 Favorsky, \\ Irkutsk 664033, Russia \\ * Corresponding author: \\ Maxim Molokeev \\ E-mail: msmolokeev@gmail.com \\ Laboratory of Crystal Physics, Kirensky Institute of Physics, Federal Research Center KSC SB RAS, \\ bld. 38 Akademgorodok 50, Krasnoyarsk 660036, Russia \\ Tel.: +7-391-249-45-07
}

$†$ Electronic supplementary information (ESI) available. See DOI:xxx

\begin{abstract}
Thiourea $(\mathrm{Tu})$ crystallizes with barbituric acid $\left(\mathrm{H}_{2} \mathrm{ba}\right)$ and 2-thiobarbituric $\left(\mathrm{H}_{2}\right.$ tba $)$ in the aqueous solution to yield co-crystals $\mathrm{H}_{2}$ ba·Tu (1) and $\mathrm{H}_{2}$ tba $\cdot \mathrm{Tu}$ (2). Powder of 1 was also obtained from individual compounds via kneading with $\mathrm{H}_{2} \mathrm{O}$. The structure of compounds was solved by the X-ray single crystal diffraction technique. In 1-2, $\mathrm{N}-\mathrm{H} \cdots \mathrm{O}, \mathrm{N}-\mathrm{H} \cdots \mathrm{S}$, $\mathrm{C}-\mathrm{H} \cdots \mathrm{S}$ and $\mathrm{C}-\mathrm{H} \cdots \mathrm{O}$ hydrogen bonds form the different 3D nets. In structure 1, centrosymmetric dimers of $\mathrm{H}_{2}$ ba and Tu molecules are formed by two $\mathrm{N}-\mathrm{H} \cdots \mathrm{O}$ and $\mathrm{N}-$ $\mathrm{H} \cdots \mathrm{S}$ hydrogen bonds, respectively. These dimers alternate in one-dimensional tapes. In compound 2, the same molecules are not bound by hydrogen bonds. Here, infinite chains are formed consisting of alternating molecules of $\mathrm{H}_{2}$ tba and $\mathrm{Tu}$. In these chains, each of the molecules is connected to the other by two $\mathrm{N}-\mathrm{H} \cdots \mathrm{S}$ hydrogen bonds. The compounds have been characterized by powder XRD, TG-DSC, and FT-IR.
\end{abstract}

Keywords: barbituric acid; 2-thiobarbituric acid; thiourea; X-ray diffraction; infrared spectroscopy 


\section{Introduction}

Barbituric acid $\left(\mathrm{H}_{2} \mathrm{ba}\right)$ is the head of a family of compounds of pharmacological interest called "barbiturates", which are used as depressants for the central nervous system, sedative hypnotics, anticonvulsants, and anesthetics [1]. As a consequence, barbituric acid and its derivatives have received considerable attention over the past decades, however, the structural investigation of their molecular co-crystals is rather limited [2]. In supramolecular chemistry, multifunctional barbituric acids can be useful building blocks for the preparation of co-crystals with an intriguing structure [3]. One of the paths to new synthons for use in crystalline engineering is to replace the strong hydrogen bond acceptor, like the $\mathrm{C}=\mathrm{O}$ group, with a weaker acceptor, like the $\mathrm{C}=\mathrm{S}$ group, in binary or ternary hydrogen-containing synthons [4]. For instance, if the $\mathrm{C}=\mathrm{O}$ group at the 2-position of barbituric acid is changed into a $\mathrm{C}=\mathrm{S}$ group, 2-thiobarbituric acid is obtained, and if the urea group $\mathrm{C}=\mathrm{O}$ is changed into a $\mathrm{C}=\mathrm{S}$ group, thiourea is obtained (Fig. 1). Barbituric and thiobarbituric acid are useful compounds in a viewpoint of the intriguing relationship between molecular and crystal structures arising from the keto-enol tautomerism characteristic of these species $[5,6]$. Thiourea $(\mathrm{Tu})$ is a very interesting compound that widely employed in the production of pharmaceutical (thiobarbiturates, sulfathiazoles) and pesticides, in the electronics industry [7], and as an additive in various electrochemical processes [8]. The molecule of Tu can be the donor of four hydrogen bonds, its thiocarbonyl sulfur can be accepted two or more hydrogen bond, and its amine $\mathrm{N}$ atoms can serve as additional acceptors of relatively weak hydrogen bonds. Due to its ability to form strong hydrogen bonds, it is used as an organocatalyst for several reactions [9], for example with imines [10]. The main aim goal of this work is to trace the effect on the supramolecular structure of co-crystals consisting of A-D compounds (Fig. 1) substitution of the strong acceptor $\mathrm{C}=\mathrm{O}$ group by the weaker acceptor $\mathrm{C}=$ $\mathrm{S}$ group. Herein, two novel co-crystals of thiourea with barbituric acid and thiobarbituric acid were synthesized and characterized by powder and single crystal X-ray diffraction, infrared spectroscopy (FT-IR) and TG-DSC methods.

\section{Experimental section}

\subsection{Reagents and synthesis}

Barbituric acid (CAS 67-52-7), thiobarbituric acid (CAS 504-17-6) with a purity of $\geq 98 \%$ and thiourea (CAS 62-56-6, 99\%) were obtained from Sigma-Aldrich and used as received. Lead(II) carbonate, $\mathrm{PbCO}_{3}$, as a reagent analytical grade (Acros), was also used without any additional purification. A single crystal of the $\mathrm{H}_{2} \mathrm{ba} \cdot \mathrm{Tu}(\mathbf{1})$ for the X-ray diffraction analysis was obtained by the following procedure. To $0.5 \mathrm{~g}$ of $\mathrm{H}_{2}$ ba in $15 \mathrm{~cm}^{3}$ of water $0.2 \mathrm{~g}$ of a solid $\mathrm{PbCO}_{3}$ and $2.4 \mathrm{~g}$ 
of $\mathrm{Tu}$ were added. The mixture was stirred for $1.5 \mathrm{~h}$ at $80^{\circ} \mathrm{C}$ and the resulting gray precipitate was filtered off. The yellow filtrate $(\mathrm{pH} \sim 4)$ was cooled to room temperature and left in air for 23 weeks until almost complete evaporation of the water. Pale yellow prismatic crystals of 1 were manually selected from the mixture. The yield was $1 \%(0.008 \mathrm{~g})$ based on $\mathrm{H}_{2}$ ba. The elemental analysis for $\mathrm{C}_{5} \mathrm{H}_{8} \mathrm{~N}_{4} \mathrm{O}_{3} \mathrm{~S}$ (1): Calc.: C, 29.4\%; H, 3.95\%; N, 27.4\%; S, 15.7\%. Found: C, 28.9\%; $\mathrm{H}, 4.10 \% ; \mathrm{N}, 27.1 \% ; \mathrm{S}, 15.4 \%$. In the absence of $\mathrm{PbCO}_{3}$ in the reaction mixture, crystals of $\mathbf{1}$ are not formed. A colorless powder of $\mathbf{1}$ was obtained by nonsolution methods, i.e. via kneading with $\mathrm{H}_{2} \mathrm{O}$ at room temperature. In a typical experiment, a mixture consisting of $0.78 \mathrm{mmol}(0.1$ g) of $\mathrm{H}_{2}$ ba and $0.78 \mathrm{mmol}(0.059 \mathrm{~g})$ of thiourea was ground in an agate mortar for an hour, adding three drops of water every $15 \mathrm{~min}$. From the aqueous solution at different reagent ratios, a mixture containing 1 and $\mathrm{H}_{2}$ ba always crystallized. Compound $\mathrm{H}_{2}$ tba $\cdot \mathrm{Tu}(2)$ was prepared by the co-crystallization of from an aqueous solution at a 5:1 molar ratio of the thiourea and $\mathrm{H}_{2}$ tba. Without an excess of thiourea, only $\mathrm{H}_{2}$ ba was crystallized. Therefore, it was necessary to ensure that thiourea concentration was high enough to encourage co-crystallization with $\mathrm{H}_{2}$ ba. For the synthesis of $2,0.10 \mathrm{~g}(0.7 \mathrm{mmol})$ of $\mathrm{H}_{2}$ tba was mixed with $0.27 \mathrm{~g}(3.5 \mathrm{mmol})$ of thiourea in water $\left(5 \mathrm{~cm}^{3}\right)$ and stirred for $0.5 \mathrm{~h}$ at $80^{\circ} \mathrm{C}$ until the reagents are completely dissolved. Then, the resulting light orange solution was slowly cooled and allowed to evaporate at room temperature ( $\mathrm{pH} \sim 3$, a multitest IPL-103 $\mathrm{pH}$ meter, Semico, Russia). After four days, the pale orange precipitate was filtered off and dried between sheets of filter paper in the air at room temperature. The yield was $80 \%(0.123 \mathrm{~g})$ based on $\mathrm{H}_{2}$ tba. A single crystal for the X-ray diffraction analysis was directly selected from the total mass of the precipitate. The elemental analysis for $\mathrm{C}_{5} \mathrm{H}_{8} \mathrm{~N}_{4} \mathrm{O}_{2} \mathrm{~S}_{2}$ (2): Calc.: C, 27.3\%; H, 3.66\%; N, 25.4\%; S, 29.1\%. Found: C, 26.9\%; H, 3.77\%; N, 25.1\%; S, 28.7.

\subsection{X-ray diffraction analysis}

The intensity patterns were collected from single crystals $\mathbf{1}$ and $\mathbf{2}$ at $100 \mathrm{~K}$ using the D8 Venture X-ray single crystal diffractometers (Bruker AXS) equipped with a CCD-detector, graphite monochromator and Mo K $\alpha$ radiation source. The absorption corrections were applied using the SADABS program. The structures were solved by the direct methods using package SHELXS and refined in the anisotropic approach for non-hydrogen atoms using the SHELXL program [11]. All hydrogen atoms were found via Fourier difference maps. Further the hydrogen atoms which are linked with $\mathrm{C}, \mathrm{N}$ atoms in the $\mathrm{H}_{2}$ ba, $\mathrm{H}_{2}$ tba, Tu molecules in $\mathbf{1 , 2}$ were positioned geometrically as riding on their parent atoms with $\mathrm{d}(\mathrm{C}-\mathrm{H})=0.93-0.98 \AA, \mathrm{d}(\mathrm{N}-\mathrm{H})=0.86-0.89 \AA$ depending on geometry and $\mathrm{U}_{\mathrm{iso}}(\mathrm{H})=1.2 \mathrm{U}_{\mathrm{eq}}(\mathrm{C}, \mathrm{N})$. The structure test for the presence of missing symmetry elements and possible voids was produced using the program PLATON [12]. The 
DIAMOND program is used for the crystal structure plotting [13]. Powder X-ray diffraction data of 1 and 2 were obtained at room temperature using diffractometer D8 ADVANCE (Bruker) equipped by a VANTEC detector with an Ni filter. The measurements were made using $\mathrm{Cu} \mathrm{K} \alpha$ radiation. The structural parameters defined by single crystal analysis were used as a basic in powder pattern Le Bail fitting, but obtained final parameters were slightly bigger (Table 1S) due to different temperatures of single crystal experiment $(100 \mathrm{~K})$ and powder diffraction experiment (300 K). The refinement was produced using program TOPAS 4.2 [14]. Low $R$-factors and good refinement results shown in (Fig. 1S, Table 1S) indicate the crystal structures of the powder samples to be representing one of the 1 and $\mathbf{2}$ bulk structure.

\subsection{Physical measurements}

Thermogravimetric analysis (TGA) was performed on the simultaneous SDT-Q600 thermal analyzer (TA Instruments, USA) under the dynamic air atmosphere $(50 \mathrm{~mL} / \mathrm{min}$ flow rate $)$ within $25^{\circ} \mathrm{C}$ to $350^{\circ} \mathrm{C}$ at the scan rate of $10^{\circ} \mathrm{C} / \mathrm{min}$. The compound weight was $8.934 \mathrm{mg}$ for 1 and $9.028 \mathrm{mg}$ for 2 . Platinum crucibles with perforated lids were used as the containers. The IR spectra were recorded as KBr pellets on a Nicolet 6700 FT-IR spectrometer (Thermo Scientific, USA, SFU CEJU, School of Petroleum and Gas Engineering) in the $4000-400 \mathrm{~cm}^{-1}$ region.

\section{Results and discussion}

\subsection{Crystal structures of 1}

The unit cell of $\mathrm{H}_{2} \mathrm{ba} \cdot \mathrm{Tu}(\mathbf{1})$ corresponds to monoclinic symmetry. Space group $P 2_{1} / n$ was determined from the statistical analysis of the reflection intensities and extinction rules. The main crystal data are shown in Table 1 . The main bond lengths $\mathrm{C}-\mathrm{N}, \mathrm{C}-\mathrm{C}, \mathrm{C}=\mathrm{S}$ (Table $2 \mathrm{~S}$ ) and the angles in $\mathbf{1}$ practically coincide with those found earlier in other related compounds [2]. $\mathrm{C}-\mathrm{O}$ bonds of $\mathrm{H}_{2}$ ba are in the range of 1.2169 (1)-1.225(1) $\AA$ and the C5B atom has two hydrogen atoms forming $-\mathrm{CH}_{2}$ group (Figure $2 \mathrm{a}$ ), i.e. $\mathrm{H}_{2}$ ba is in the keto form. The asymmetric part of the unit cell contains one $\mathrm{H}_{2}$ ba molecule and one Tu molecule (Fig. 1a). There are nine intermolecular hydrogen bonds $\mathrm{N}-\mathrm{H} \cdots \mathrm{O}, \mathrm{N}-\mathrm{H} \cdots \mathrm{S}, \mathrm{C}-\mathrm{H} \cdots \mathrm{O}$, and $\mathrm{C}-\mathrm{H} \cdots \mathrm{S}$ in the structure (Table $3 \mathrm{~S}$ ) which form a very complex 3D structure with the shortest ring motifs $\mathrm{R}_{2}{ }^{1}(6), \mathrm{R}_{2}{ }^{2}(6)$, $\mathrm{R}_{2}{ }^{2}(8), \mathrm{R}_{3}{ }^{2}(8), \mathrm{R}_{4}{ }^{3}(10), \mathrm{R}_{4}{ }^{3}(12)$ and $\mathrm{R}_{5}{ }^{5}(20)$ (Figure 3a). All donor and acceptor sites of $\mathrm{H}_{2} \mathrm{ba}$ and Tu molecules were involved in the interaction. Each $\mathrm{H}_{2}$ ba molecule self-assembled via $\mathrm{N}$ $\mathrm{H} \cdots \mathrm{O}$ homosynthon dimer motif with graph set $\mathrm{R}_{2}^{2}(8)$ forming a pair. Also two Tu molecules self-assembled via $\mathrm{N}-\mathrm{H} \cdots \mathrm{S}$ homosynthon dimer motif with graph set $\mathrm{R}_{2}{ }^{2}(8)$. These pairs are connected with the $\mathrm{H}_{2}$ ba molecules by $\mathrm{N}-\mathrm{H} \cdots \mathrm{S}, \mathrm{N}-\mathrm{H} \cdots \mathrm{O}$ and $\mathrm{C}(5 \mathrm{~B})-\mathrm{H}(52) \cdots \mathrm{S}$ hydrogen 
bonds, yielding a three-dimensional network. The most prominent 2D net in the plane based on $c$ and $a-b$ vectors can be marked (Figure 3a).

The hydrogen bonds system in $\mathbf{1}$ differs significantly from the one found in the three polymorphs of $\mathrm{H}_{2}$ ba.Urea co-crystal (I-III) [15]. Despite the similarity of thiourea and urea, supramolecular motifs in $\mathbf{1}$ and $\mathbf{I}-\mathbf{I I I}$ are almost always different (Figure 3a, Figure 3S). The common thing for these structures is that all hydrogen atoms in $\mathrm{Tu}$ and Urea participate in $\mathrm{H}$ bonds and there are supramolecular motifs of $\mathrm{R}_{2}{ }^{2}(8)$. Similarly to compound $\mathbf{1}$, in polymorph III dimers of urea and dimers of barbituric acid molecules alternate in one-dimensional tapes. In polymorph I, Urea dimers and chains of barbituric acid molecules are observed. As in 1, in a cocrystal Barbital $\cdot$ Urea (Barbital $=5,5$-diethylbarbituric acid), two $\mathrm{N}-\mathrm{H} \cdots \mathrm{O}$ hydrogen bonds has Urea as an NH-donor and barbital as a bifurcated O-acceptor forming supramolecular motif $\mathrm{R}_{2}{ }^{1}(6)$ [16], and in another $\mathrm{N}-\mathrm{H} \cdots \mathrm{O}$ hydrogen bond the barbital acts as an $\mathrm{NH}$-donor and Urea behaves as an O-atom acceptor. Topological analysis of the net, using simplification that $\mathrm{H}_{2}$ ba and $\mathrm{Tu}$ are just nodes, revealed that this is binodal (5-c)(7-c) net with point symbol $\left(3.4^{7} \cdot 5^{2} \cdot 6^{11}\right)\left(3^{2} \cdot 4^{4} \cdot 5 \cdot 6^{2} \cdot 7\right)$ which is new [17].

\subsection{Crystal structures of 2}

The unit cell of $\mathrm{H}_{2} \mathrm{tba} \cdot \mathrm{Tu}$ (2) also corresponds to monoclinic symmetry, however with another space group $P 2{ }_{1} / \mathrm{m}$. The crystal structure was solved and the refinement was stopped at $R_{B}=6 \%$. Checking crystal structure and possible unit cell orientations revealed possible twinning of the structure. The main domain rotation about [201] direction in the real space leads to a second domain which coincides with main one by nodes (Figure 2S). The TWIN instruction with matrix (-1 00 0; $010 ; 0 ; 101)$ was used and BASF coefficient was refined. In the result the $R_{B}$-factor decreased down to $2.6 \%$ and BASF $=0.0462$ (7) means that the second domain has a total amount of $\sim 4.62 \%$ only. The main crystal data are shown in Table 1 . The main bond lengths $\mathrm{C}-\mathrm{N}, \mathrm{C}-\mathrm{C}, \mathrm{C}-\mathrm{S}$ (Table $2 \mathrm{~S}$ ) and the angles in $\mathrm{H}_{2}$ tba (keto isomer) and $\mathrm{Tu}$ coincide with those given in the literature [2]. The asymmetric part of the unit cell contains one $\mathrm{H}_{2}$ tba molecule and one Tu molecule (Figure 2b). There are four intermolecular hydrogen bonds $\mathrm{N}-$ $\mathrm{H} \cdots \mathrm{O}, \mathrm{N}-\mathrm{H} \cdots \mathrm{S}, \mathrm{C}-\mathrm{H} \cdots \mathrm{S}$ and $\mathrm{C}-\mathrm{H} \cdots \mathrm{O}$ in the structure (Table 3S) which form a 3D net. The most prominent a 2D net in the plane based on $b$ and $a+c$ axis can be marked (Figure $3 \mathrm{~b}$ ), and the shortest ring motifs in them are $\mathrm{R}_{2}{ }^{2}(8), \mathrm{R}_{4}{ }^{3}(12), \mathrm{R}_{4}{ }^{3}(14)$. Unlike $\mathbf{1}$, in 2 there are no moderate hydrogen bonds between molecules of the same type. In structure 2 there are infinite zigzag chains along the axis $b$ consisting of alternating $\mathrm{H}_{2}$ tba and Tu molecules formed via $\mathrm{N}-\mathrm{H} \cdots \mathrm{S}$ hydrogen bonds $\left(\mathrm{R}_{2}{ }^{2}(8)\right.$ motif). These chains are connected by $\mathrm{N}-\mathrm{H} \cdots \mathrm{O}$ hydrogen bonds. Two thiourea and two $\mathrm{H}_{2}$ tba molecules via $\mathrm{N}-\mathrm{H} \cdots \mathrm{O}, \mathrm{N}-\mathrm{H} \cdots \mathrm{S}$ hydrogen bonds form 12-membered and 14-membered cycles $\left(\mathrm{R}_{4}{ }^{3}(12), \mathrm{R}_{4}{ }^{3}(14)\right.$ motifs). In co-crystals $\mathbf{1 - 2}$, thiourea is a trifurcated S- 
acceptor (two $\mathrm{N}-\mathrm{H} \cdots \mathrm{S}$ and one $\mathrm{C}-\mathrm{H} \cdots \mathrm{S}$ interactions) (Figure 3b, Table 3S). Co-crystals 1-2 contain $\mathrm{H}_{2}$ ba and $\mathrm{H}_{2}$ tba molecule in the form of a keto isomer. It is shown that the thermodynamically stable crystals of $\mathrm{H}_{2}$ ba and $\mathrm{H}_{2}$ tba are formed by molecules of the enol tautomer [5] and both the keto and enol tautomers [6] respectively. However, as a rule, both molecules of $\mathrm{H}_{2}$ ba and $\mathrm{H}_{2}$ tba in co-crystals are keto tautomers [2] and only in salt co-crystal $\left(\mathrm{PipeH}^{+}\right)\left(\mathrm{Htba}^{-}\right) \cdot \mathrm{H}_{2}$ tba (Pipe = piperidine) the $\mathrm{H}_{2}$ tba molecule is in the enol form [18]. Analysis of possible $\pi-\pi$ interactions in $\mathbf{1}$ and $\mathbf{2}$ didn't reveal them. Topological analysis using ToposPro program [17] showed that this 3D net is binodal (4-c)(6-c) net with point symbol $\left(4^{4} \cdot 6^{2}\right)\left(4^{9} \cdot 6^{6}\right)$ which is known as 4,6L69. There are four compounds from CCDC have the same topological net: AYACUZ, GUKMII, GUKNEF and KALCEH.

\subsection{IR spectroscopy}

The IR spectra of thiourea, barbituric acid, 2-thiobarbituric acid and 1-2 dispersed in a $\mathrm{KBr}$ pellet are shown in Fig. 7S, 8S. The bands obtained for the starting compounds are virtually identical to those reported previously for solid $\mathrm{Tu}$ [19], $\mathrm{H}_{2}$ ba and $\mathrm{H}_{2}$ tba [20-23]. The FTIR patterns of 1 (Fig 5S, curve 3) and 2 (Fig 6S, curve 3) display the characteristic absorption bands of $\mathrm{Tu}$ and barbituric/thiobarbituric acid, showing their multicomponent crystalline composition. The resulting spectra of co-crystals are different from the superimposed spectra of the starting materials and this indicates the formation of new compounds. IR spectra contain a large number of bands that complicate their assignment. Thus, the assignment of the IR vibrational bands to the corresponding normal modes is based on previous studies [19-23]. In the IR spectra of $\mathrm{H}_{2}$ ba (Fig 5S, curve 1), the strong bands at 1754, 1710 and $1693 \mathrm{~cm}^{-1}$ are associated with the $v(\mathrm{CO})$ vibration [21, 22]. In the IR spectra of 1 (Fig 5S, curve 3), they are observed at 1756, 1720 and $1691 \mathrm{~cm}^{-1}$, which agrees with the presence of the neutral $\mathrm{H}_{2}$ ba molecule, i.e., with the formation of organic co-crystal. A strong band at $1614 \mathrm{~cm}^{-1}$ in the IR spectra of $\mathbf{1}$ and $\mathbf{2}$ is assigned to $\delta(\mathrm{N}-\mathrm{H})$ of $\mathrm{Tu}$ [19] and it confirms its the presence in the compounds. The decrease in the intensity of the band at $730 \mathrm{~cm}^{-1}(v(C S))$ for free Tu in the spectra of co-crystals is due to the participation of thiourea atom $S$ in three hydrogen bonds (Fig. 2). The strong bands at 1742, 1704 and $1655 \mathrm{~cm}^{-1}$ in the IR spectra of $\mathrm{H}_{2}$ tba $\mathrm{Tu}$ (Fig 6S, curve 3) are assigned to $v(\mathrm{CO})$ vibration of $\mathrm{H}_{2}$ tba $[21,23]$ and it confirms its the presence in the neutral form. The bands assigned to the $v(\mathrm{CO})$ vibration for $\mathrm{Htba}^{-}$and $\mathrm{Hba}^{-}$ions are located below $1700 \mathrm{~cm}^{-1}$ [24, 25]. Thus, the IR spectra confirm that compounds $\mathbf{1}$ and $\mathbf{2}$ are molecular co-crystals.

\subsection{Thermal decomposition}

Results revealed that the melting point of the co-crystals distinct from the starting components. A comparison of the corresponding TG and DSC curves in air shows that the stages of the thermal 
decomposition coincide. According to the TG curves, the mass of samples remains unchanged to $\sim 190^{\circ} \mathrm{C}$ (Fig. 5S, 6S), which confirms their anhydrous nature. In the range of $190-250{ }^{\circ} \mathrm{C}$, the mass of compounds $(\mathrm{m})$ decreases rapidly $(\Delta \mathrm{m} \approx 27 \%$ for 1 and 2$)$, and then to $\sim 320{ }^{\circ} \mathrm{C}$, the mass reduction occurs much more slowly. Co-crystal $\mathrm{H}_{2} \mathrm{ba} \cdot \mathrm{Tu}$ showed two endothermic peaks, one corresponding to melting $\left(177^{\circ} \mathrm{C}\right)$ and the other to decomposition $\left(238{ }^{\circ} \mathrm{C}\right)$. Also, the oxidative decomposition was accompanied by an exothermic effect at $212{ }^{\circ} \mathrm{C}$. As $\mathbf{1}, \mathrm{H}_{2} \mathrm{tba} \cdot \mathrm{Tu}$ exhibited two endothermic effects, one corresponding to the melting point $\left(214^{\circ} \mathrm{C}\right)$ and the other to decomposition $\left(232^{\circ} \mathrm{C}\right)$. The melting point of $\mathrm{H}_{2} \mathrm{ba} \cdot \mathrm{Tu}\left(177^{\circ} \mathrm{C}\right)$ was found lower than those for $\mathrm{Tu}\left(180-182{ }^{\circ} \mathrm{C}\right)$ [7] and $\mathrm{H}_{2}$ ba $\left(245.0{ }^{\circ} \mathrm{C}\right)$ [26], that is, co-crystal 1 less stable than the starting reagents. While the $\mathrm{H}_{2}$ tba $\cdot \mathrm{Tu}$ co-crystal $\left(214^{\circ} \mathrm{C}\right)$ proved to be more stable than $\mathrm{Tu}$, but less stable than $\mathrm{H}_{2}$ tba $\left(250.6{ }^{\circ} \mathrm{C}\right.$ [27]). According to the classification of Perlovich [28], the cocrystal 1 with melting temperature lower than those of the individual components refers to group III. The melting temperature of crystal $\mathbf{2}$ is between the values of the individual components, therefore it belongs to group I.

\section{Conclusions}

Crystals of 1 with very low yields were obtained by the interaction of $\mathrm{H}_{2} \mathrm{ba}, \mathrm{PbCO}_{3}$, and thiourea in water. In the absence of $\mathrm{PbCO}_{3}$ in the reaction mixture, these crystals were not formed. Powder of 1 was obtained from $\mathrm{H}_{2}$ ba and Tu via kneading with $\mathrm{H}_{2} \mathrm{O}$ at room temperature. Cocrystal $\mathrm{H}_{2}$ tba $\mathrm{Tu}$ (2) with high yields was prepared by the co-crystallization of the individual compounds from an aqueous solution containing a fivefold molar excess of thiourea. Based on the results of the work [15], it can be assumed that by varying the crystallization conditions, new polymorphs of barbituric acids and thiourea will also be obtained. The co-crystallization results of thiourea and urea [15] with barbituric and 2-thiobarbituric acids show that the exchange of one $\mathrm{C}=\mathrm{O}$ group as a hydrogen bond acceptor with a weaker $\mathrm{C}=\mathrm{S}$ group in $\mathrm{H}_{2}$ ba and urea considerably changes the supramolecular structure of the co-crystals. The substitution of the oxygen atom in barbituric acid by a sulfur atom reduces the number of hydrogen bonds (Table 2). The dominant $\mathrm{H}$-bonds in compounds $\mathbf{1}$ and $\mathbf{2}$ are the $\mathrm{N}-\mathrm{H} \cdots \mathrm{O}$ and $\mathrm{N}-\mathrm{H} \cdots \mathrm{S}$ interactions, which together with weak $\mathrm{C}-\mathrm{H} \cdots \mathrm{S}$ and $\mathrm{C}-\mathrm{H} \cdots \mathrm{O}$ hydrogen bonds form a three-dimensional network (Fig. 2, 3). Co-crystal 1 has the new topological net. In 1-2, thiourea is a trifurcated Sacceptor. In structure $1, \mathrm{H}_{2}$ ba and Tu molecules self-assembled via $\mathrm{N}-\mathrm{H} \cdots \mathrm{O}$ and $\mathrm{N}-\mathrm{H} \cdots \mathrm{S}$ homosynthon dimers $\left(\mathrm{R}_{2}^{2}(8)\right.$ motif), respectively (Fig.3a). In 2, infinite zigzag chains are formed, which consist of alternating $\mathrm{H}_{2}$ tba and Tu molecules, bound by $\mathrm{N}-\mathrm{H} \cdots \mathrm{S}$ hydrogen bonds. These chains are connected by $\mathrm{N}-\mathrm{H} \cdots \mathrm{O}$ hydrogen bonds forming $\mathrm{R}_{4}{ }^{3}(12), \mathrm{R}_{4}{ }^{3}(14)$ motifs (Fig.3b). Analysis of the IR spectra confirms that compounds $\mathbf{1}$ and $\mathbf{2}$ are molecular co-crystals. 
When heated, they remain unchanged to $\sim 190^{\circ} \mathrm{C}$ (Fig. 6S, 7S), which confirms their anhydrous nature.

\section{Supplementary data}

The crystallographic data (excluding structure factors) for the structural analysis have been deposited with Cambridge Crystallographic Data Centre ((1) - CCDC \# 1851385; (2) CCDC \# 1851498). The information may be obtained free of charge from The Director, CCDC, 12 Union Road, Cambridge CB2 1EZ, UK (Fax: +44(1223)336-033, E-mail: deposit@ccdc.cam.ac.uk, or www: www.ccdc.cam.ac.uk).

\section{Acknowledgements}

The study was carried out within the public task of the Ministry of Education and Science of the Russian Federation to the Siberian Federal University (4.7666.2017/BP) in 2017-2019. X-ray data from single crystals were obtained with use the analytical equipment of Baikal Center of collective use of SB RAS and with use the analytical equipment of Krasnoyarsk Center of collective use of SB RAS. 


\section{References}

1. G.L. Patrick, An Introduction to Medicinal Chemistry, 4th ed., Oxford University

Press, Oxford, 2009, pp. 752.

2. Cambridge Structural Database, Univ. of Cambridge, Cambridge, UK, 2017.

3. 1. K.T. Mahmudov, M.N. Kopylovich, A.M. Maharramov, M.M. Kurbanova, A.V. Gurbanov, A.J.L. Pombeiro, Coord. Chem. Rev. 265 (2014) 1-37..

4. W.M. Hützler, E. Egerta, M. Bolte, Acta Cryst. (2016). C72, 705-715.

5. M.G. Marshall, V. Lopez-Diaz, B.S. Hudson, Angew. Chem., Int. Ed., 2016, 55, 1309, DOI: 10.1002/anie.201508078 IYAQOP02

6. M.R. Chierotti, L. Ferrero, N. Garino, R. Gobetto,L. Pellegrino, D. Braga, F. Grepioni, L. Maini, Chem. Eur. J. 2010, 16, 4347 - 4358

7. C. Pizzarini, J. Phys. Chem. A 2012. 116. 4381-4387.

8. Ulman, A. Chem. Rev. 1996, 96, 1533.

9. Sigman, M. S.; Jacobsen, E. N. J. Am. Chem. Soc. 1998, 120 (19), 4901-4902.

10. V.d.P.N. Nziko, S. Scheiner, J. Org. Chem. 2015, 80, 10334-10341

DOI:10.1021/acs.joc.5b01985.

11. G.M. Sheldrick, Acta Cryst. A 64 (2008) 112-122.

12. PLATON - a Multipurpose Crystallographic Tool, Utrecht University, Utrecht, The Netherlands, 2008.

13. K. Brandenburg, M. Berndt, DIAMOND - Visual Crystal Structure Information System CRYSTAL IMPACT, Postfach 1251, D-53002 Bonn.

14. Bruker AXS TOPAS V4: General profile and structure analysis software for powder diffraction data. - User's Manual, Bruker AXS, Karlsruhe, Germany, 2008.

15. M. Gryl, A. Krawczuk, K. Stadnicka, Acta Crystallogr. B64 (2008) 623-632

16. T.S. Thakur, Y. Azim, T. Srinu, G.R. Desiraju, Current Sci., V. 98, NO. 6, 2010 793-802.

17. V.A. Blatov, A.P. Shevchenko, D.M. Proserpio, Cryst. Growth Des. 14 (2014) 3576.

18. N.N. Golovnev, M.S. Molokeev, I.V. Sterkhova, I.I. Golovneva, J. Struct. Chem. 2016, 57(6), 1266.

19. G.M.S. El-Bahy, B.A. El-Sayed, A.A. Shabana, Vibrational Spectroscopy 31 (2003) 101107.

20. N.A. Smorygo, B.A. Ivin, Khim. Geterotsikl. Soedin. 1975, 10, 1402.

21. J. T. Bojarski, J. L. Mokrosz, H. J. Barton, M. H. Paluchowska, Adv. Heterocycl. Chem. 1985, 38, 229.

22. L. Dorofeev, Pharm. Chem. J. 2004, 38(12), 693.

23. E . Mendez, M.F. Cerda, J.S. Gancheff, J. Torres, C. Kremer, J. Castiglioni, M. Kieninger, O.N. Ventura. J. Phys. Chem. C, 111, 3369 (2007) 
24. N.N. Golovnev, M.S. Molokeev, M.K. Lesnikov, S.N. Vereshchagin, Russ. J. Inorg. Chem. 2017, Vol. 62, No. 6, 746-750.

25. N.N. Golovnev, M.S. Molokeev, I.V. Sterkhova, V.V. Atuchin, M.Y. Sidorenko, J. Coord. Chem., 2016, V.69, NO. 21, 3219-3230.

26. M. R. Chierotti, K. Gaglioti, R. Gobetto, D. Braga, F. Grepioni, L. Maini, CrystEngComm 2013, 15, 7598 .

27. N. N. Golovnev, M. S. Molokeev, L. S. Tarasova, V. V. Atuchin, N. I. Vladimirova, J. Mol. Struct. 2014, 1068, 216.

28. G.L. Perlovich, CrystEngComm. 7 (x) (2015) 7019-7028 DOI: 10.1039/c5ce00992h

\section{Graphical Abstract}

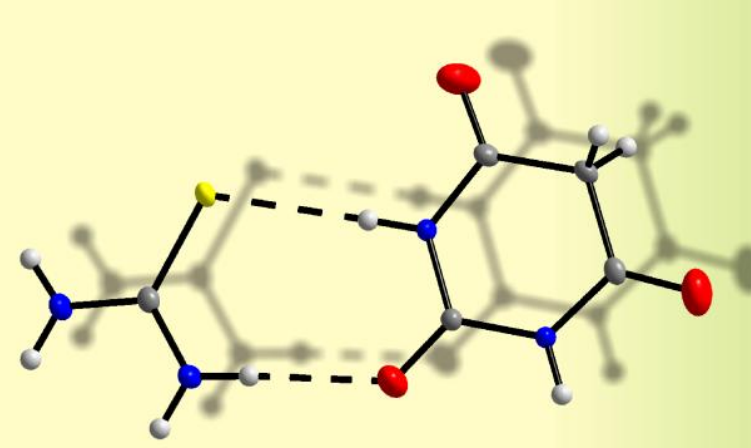

Thiourea Barbituric acid

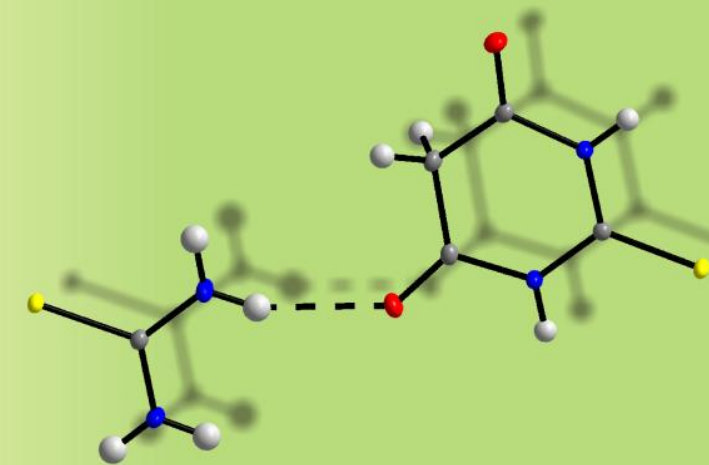

Thiourea 2-Thiobarbituric acid 
Table 1. Crystal structure parameters of 1-2

\begin{tabular}{|c|c|c|}
\hline Single crystal & $\mathrm{H}_{2} \mathrm{ba} \cdot \mathrm{Tu}(\mathbf{1})$ & $\mathrm{H}_{2} \mathrm{tba} \cdot \mathrm{Tu}(\mathbf{2})$ \\
\hline Moiety formula & $\mathrm{C}_{5} \mathrm{H}_{8} \mathrm{~N}_{4} \mathrm{O}_{3} \mathrm{~S}$ & $\mathrm{C}_{5} \mathrm{H}_{8} \mathrm{~N}_{4} \mathrm{O}_{2} \mathrm{~S}_{2}$ \\
\hline Dimension (mm) & $0.14 \times 0.27 \times 0.40$ & $0.50 \times 0.35 \times 0.20$ \\
\hline Color & Pale yellow & Pale pink \\
\hline Molecular weight & 204.21 & 220.27 \\
\hline Temperature (K) & 100 & 100 \\
\hline Space group, $Z$ & $P 2_{1} / n, 4$ & $P 2_{1} / m, 2$ \\
\hline$a(\AA)$ & $8.3653(3)$ & $6.8424(4)$ \\
\hline$b(\AA)$ & $6.4230(2)$ & $8.4573(5)$ \\
\hline$c(\AA)$ & $15.8722(6)$ & $8.4203(5)$ \\
\hline$\beta\left({ }^{\circ}\right)$ & $95.754(1)$ & $113.421(2)$ \\
\hline$V\left(\AA^{3}\right)$ & $848.52(5)$ & $447.12(5)$ \\
\hline$\rho_{\text {calc }}\left(\mathrm{g} / \mathrm{cm}^{3}\right)$ & 1.599 & 1.636 \\
\hline$\mu\left(\mathrm{mm}^{-1}\right)$ & 0.363 & 0.568 \\
\hline $\begin{array}{l}\text { Reflections } \\
\text { measured }\end{array}$ & 20224 & 20210 \\
\hline $\begin{array}{l}\text { Reflections } \\
\text { independent }\end{array}$ & 2466 & 1385 \\
\hline $\begin{array}{l}\text { Reflections with } F \\
>4 \sigma(F)\end{array}$ & 2291 & 1359 \\
\hline $2 \theta_{\max }\left({ }^{\circ}\right)$ & 60.06 & 60.13 \\
\hline$h, k, l$ - limits & $\begin{array}{l}-11 \leq h \leq 8 \\
-9 \leq k \leq 9 \\
-22 \leq l \leq 22\end{array}$ & $\begin{array}{c}-9 \leq h \leq 9 \\
-11 \leq k \leq 11 \\
-11 \leq l \leq 11\end{array}$ \\
\hline$R_{\text {int }}$ & 0.0302 & 0.0356 \\
\hline $\begin{array}{l}\text { The weighed } \\
\text { refinement of } F^{2}\end{array}$ & $\begin{array}{l}w=1 /\left[\sigma^{2}\left(F_{\mathrm{o}}{ }^{2}\right)+(0.0293 P)^{2}+0.5\right. \\
397 \mathrm{P}]\end{array}$ & $\begin{array}{l}w=1 /\left[\sigma^{2}\left(F_{\mathrm{o}}{ }^{2}\right)+(0.0196 P)^{2}+0.3733\right. \\
\mathrm{P}]\end{array}$ \\
\hline $\begin{array}{l}\text { Number of } \\
\text { refinement } \\
\text { parameters }\end{array}$ & 130 & 11 \\
\hline$R 1\left[F_{\mathrm{o}}>4 \sigma\left(F_{\mathrm{o}}\right)\right]$ & 0.0299 & 0.0262 \\
\hline$w R 2$ & 0.0718 & 0.0642 \\
\hline Goof & 1.060 & 1.134 \\
\hline$\Delta \rho_{\max }\left(\mathrm{e} / \AA^{3}\right)$ & 0.478 & 0.364 \\
\hline$\Delta \rho_{\min }\left(\mathrm{e} / \AA^{3}\right)$ & -0.314 & -0.263 \\
\hline$(\Delta / \sigma)_{\max }$ & $<0.001$ & 0.001 \\
\hline
\end{tabular}



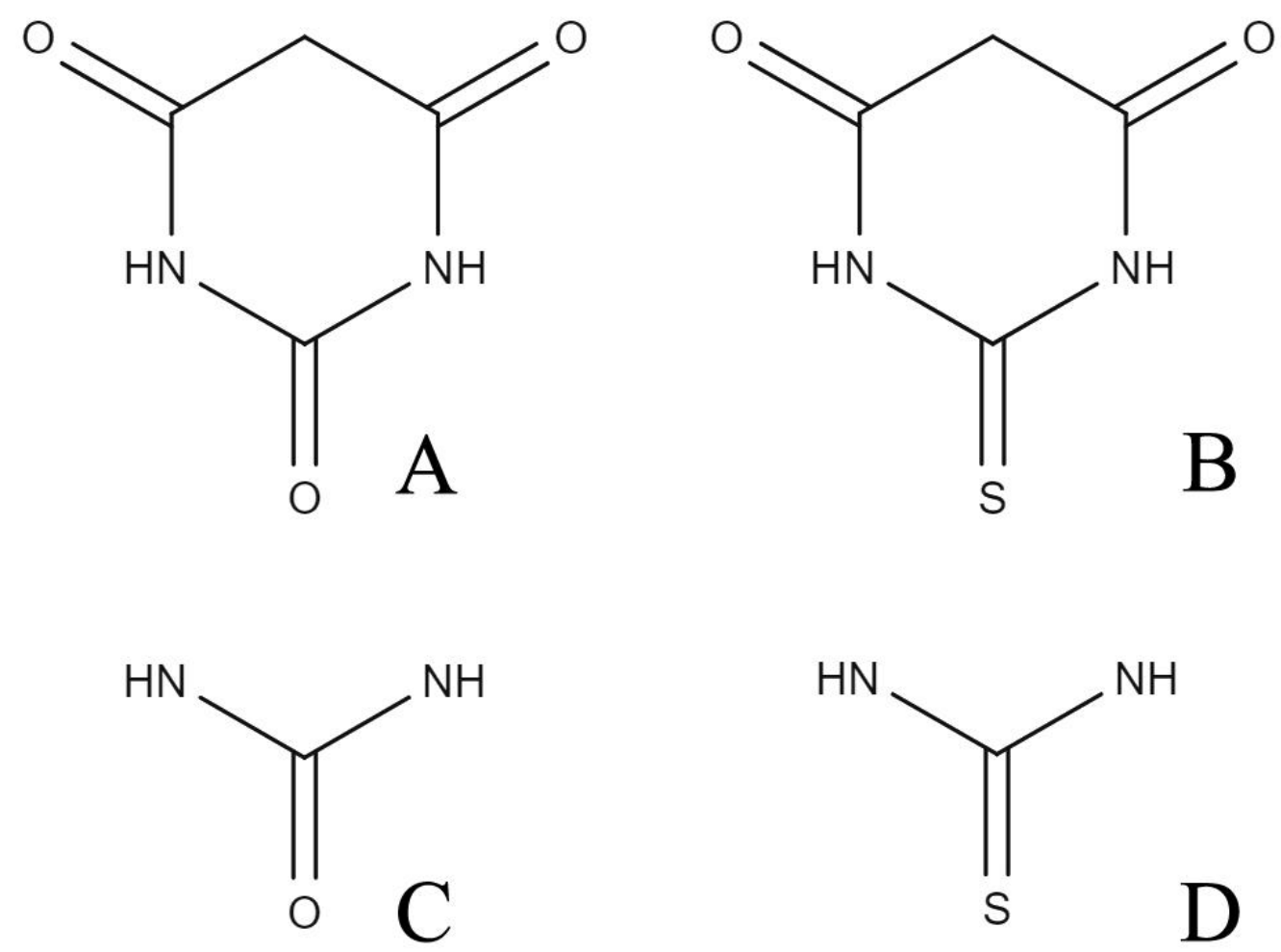

Fig. 1 Schemes of barbituric acid (A), 2-thiobarbituric acid (B), urea (C) and thiourea (D). 


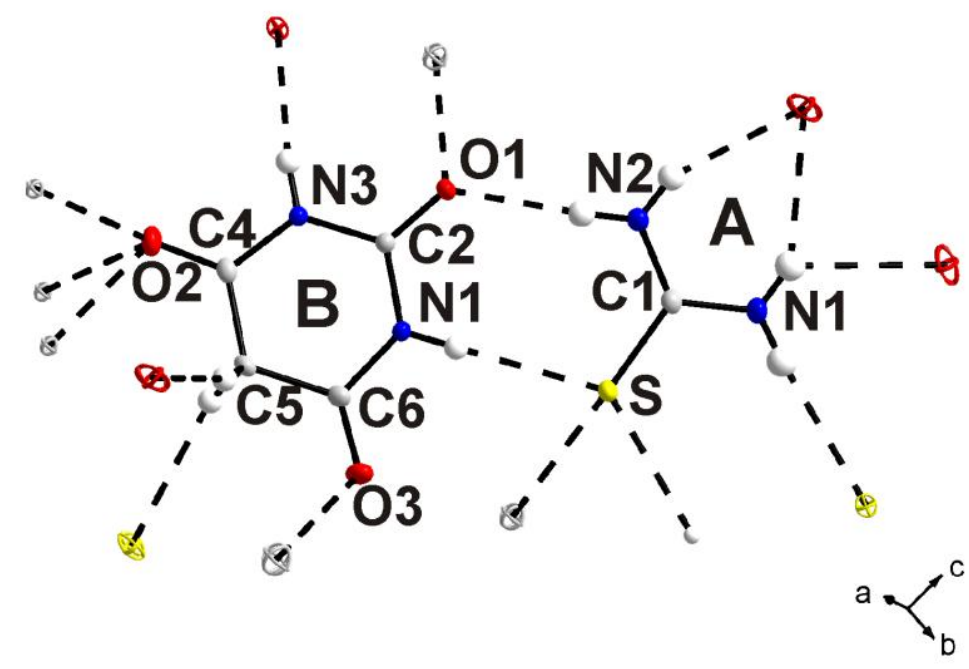

a)

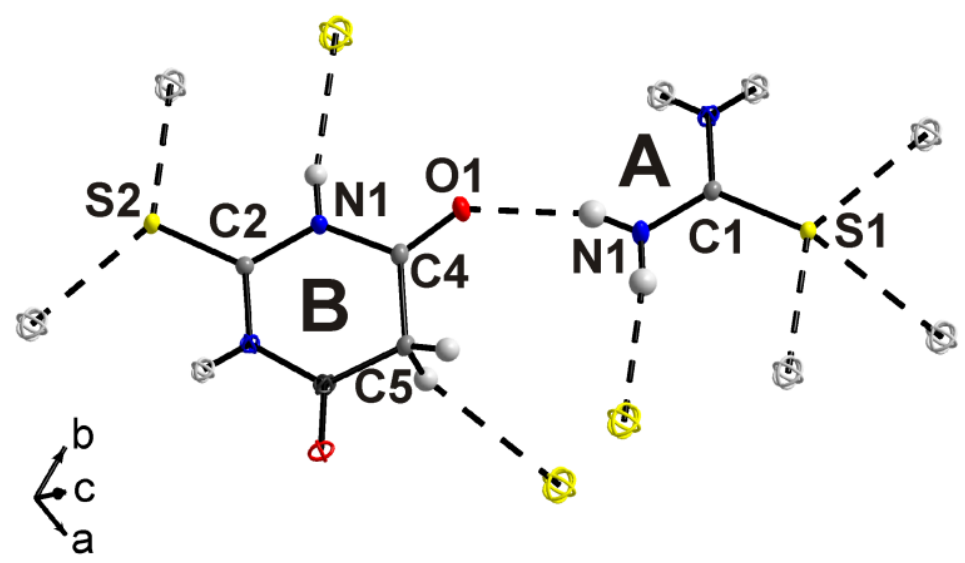

b)

Fig. 2 The asymmetric unit of the $\mathrm{H}_{2} \mathrm{ba} \cdot \mathrm{Tu}(\mathrm{a}), \mathrm{H}_{2} \mathrm{tba} \cdot \mathrm{Tu}(\mathrm{b})$ unit cell. Symmetry independent, different molecules are marked by A, B labels. All atoms in the asymmetric unit are labeled. The neighboring symmetry-generated atoms are represented by principal ellipses with an individual color. The intermolecular hydrogen bonds are represented by dashed lines. The ellipsoids are drawn at the $50 \%$ probability level, except for the hydrogen atoms represented by spheres. 


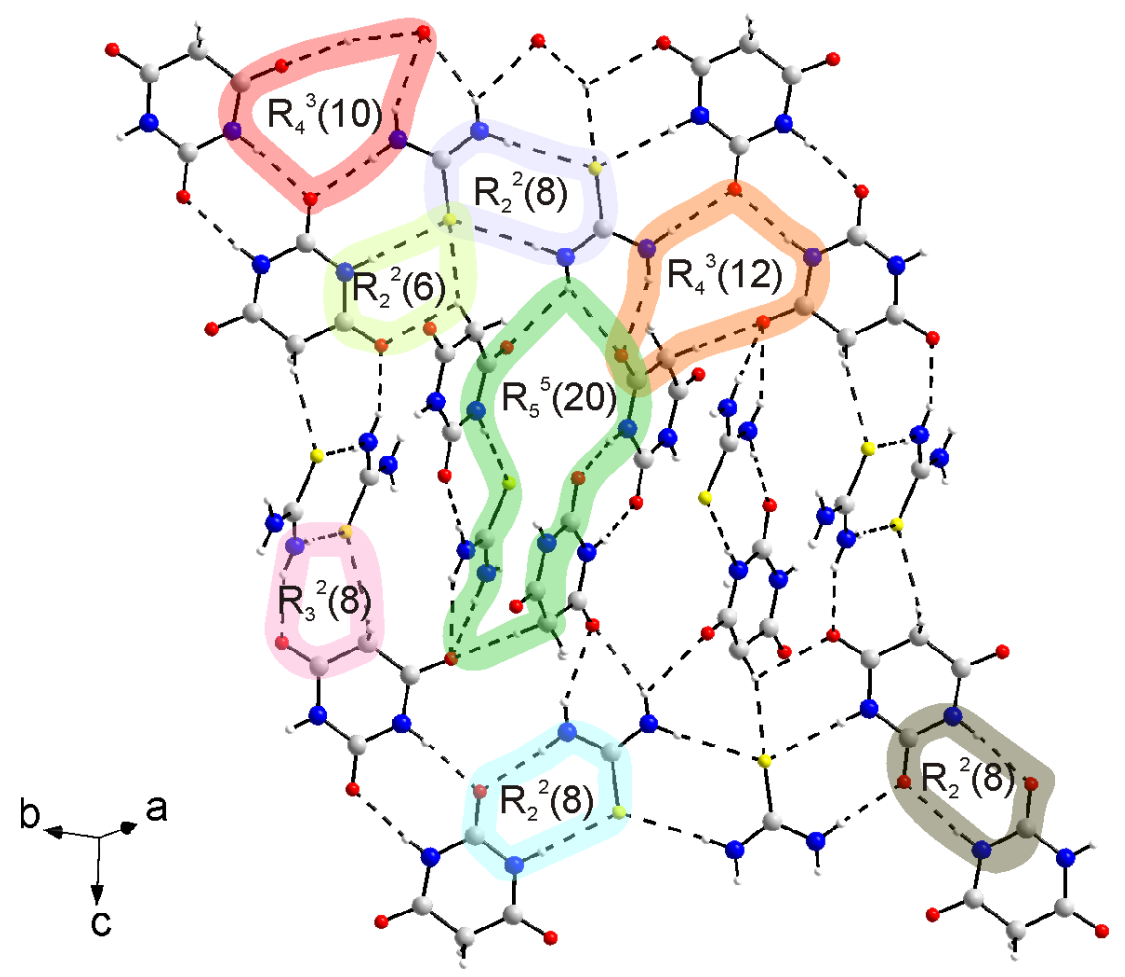

a)

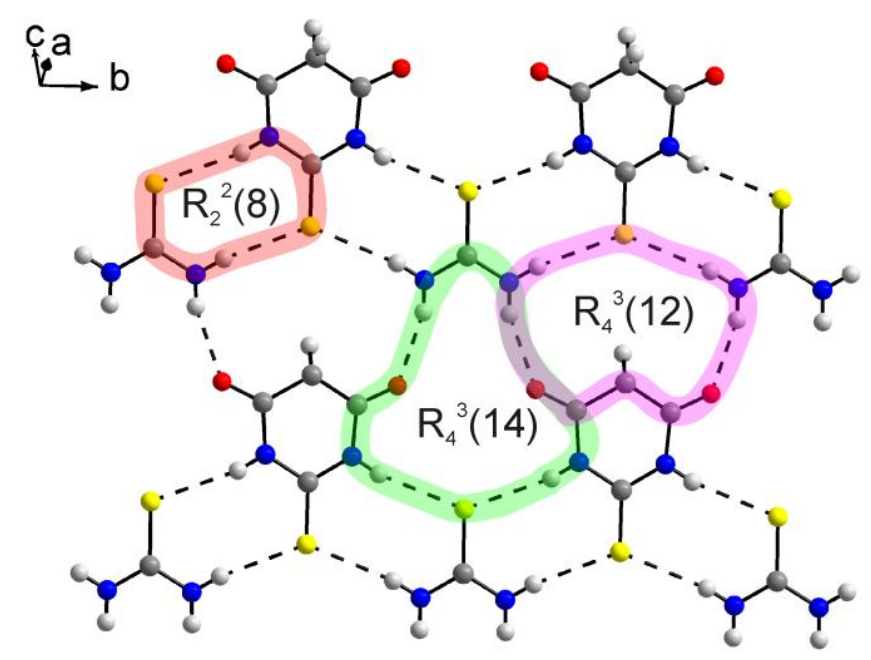

b)

Fig. 3 Hydrogen bonding in 1 (a) and 2 (b). The H-bonds are marked by dashed lines, the Hbond motifs are marked by circles. 